\title{
QUALIDADE DE ÁGUA COMO ALICERCE PARA A PRODUÇÃO SUSTENTÁ VEL DE PEIXES À PEQUENOS PRODUTORES
}

\author{
WATER QUALITY AS A FOUNDATION FOR \\ SUSTAINABLE FISH PRODUCTION FOR SMALL \\ PRODUCERS
}

\author{
Matheus Antonio do Amaral 38 \\ Rayane Seibt Moraes ${ }^{1}$ \\ Wesley Paulo da Silva ${ }^{1}$ \\ Daniele Menezes Albuquerque ${ }^{39}$ \\ Claucia Aparecida Honorato ${ }^{2}$ \\ Dacley Hertes $\mathrm{Neu}^{2}$
}

Resumo: O objetivo deste projeto foi instruir alunos do curso de Engenharia de Aquicultura da Universidade Federal da Grande Dourados - UFGD e fazer com que eles repassassem as informações que aprenderam em sala de aula a pequenos produtores rurais, não necessariamente produtores de peixes, mas que tivessem algum interesse na área. Este projeto teve duração de 1 ano e as visitas às propriedades ocorreram no último semestre de 2019. Para a conversa entre os acadêmicos e os produtores rurais ser efetuada, nove propriedades foram visitadas, todas no Assentamento Itamarati, localizado no município de Ponta Porã - MS. Nessas propriedades foram feitas análises de água como, oxigênio dissolvido $\left(\mathrm{mg} \mathrm{L}^{-1}\right), \mathrm{pH}$, transparência $(\mathrm{cm})$, temperatura $\left({ }^{\circ} \mathrm{C}\right)$, alcalinidade $(\mathrm{mg}$ $\left.\mathrm{L}^{-1}\right)$, amônia total $\left(\mathrm{mg} \mathrm{L}^{-1}\right)$, amônia tóxica $\left(\mathrm{mg} \mathrm{L}^{-1}\right)$ e nitrito $\left(\mathrm{mg} \mathrm{L}^{-1}\right)$, e os acadêmicos explicavam aos produtores como esses parâmetros deveriam permanecer no intuito de obter uma produção de peixes sustentável. Nesse ínterim, após as coletas de água, os produtores rurais foram instruídos a como verificar os parâmetros e como os mesmos deveriam permanecer. Para isso, fichas elaboradas foram disponibilizadas. Foi possível observar que a falta de informação no campo deve ser esclarecida, para que haja maior produção de peixes, com segurança e sustentabilidade. A qualidade de água é um dos primeiros pontos que devem ser analisados antes da instalação de uma atividade aquícola e os alunos que participaram desse projeto conseguiram converter as palavras utilizadas na academia para que os produtores rurais pudessem compreender a importância das verificações periódicas.

Palavras-chave: meio ambiente, piscicultura, transferência de conhecimentos.

\footnotetext{
38 Discente do curso de Engenharia de Aquicultura da Universidade Federal da Grande DouradosUFGD.

${ }^{39}$ Docente do curso de Engenharia de Aquicultura da Universidade Federal da Grande DouradosUFGD.
} 
Abstract: The purpose of this work was to instruct the students from the aquaculture engineering course of Federal University of Great Dourados - UFGD and make them pass along the information they've learnt at classroom to small farmers, not necessarily fish producers, but anyone who had any interest in the field. The project lasted for one year, and the visits to properties happened in the last semester of 2019. To make the conversation between producers and academics happen, nine properties were visited, all in Itamarati Settlement, located in the municipality of Ponta Porã - MS. In those locations were made analyses of water like, oxygen dissolved $\left(\mathrm{mg} \mathrm{L}^{-1}\right), \mathrm{pH}$, transparency $(\mathrm{cm})$, temperature $\left({ }^{\circ} \mathrm{C}\right)$, alkalinity $\left(\mathrm{mg} \mathrm{L}^{-1}\right)$, total ammonia $\left(\mathrm{mg} \mathrm{L}^{-1}\right)$, toxic ammonia $\left(\mathrm{mg} \mathrm{L}^{-1}\right)$ and nitrite $\left(\mathrm{mg} \mathrm{L}^{-1}\right)$, and the academics explained to the producers how those parameters should stay, and how to check them, to get a sustainable fish production. To make it happen, some forms were left to the producers. It was noticed that the lack of information in field is a gap that has to be filled, so it'll increase the fish production, with security and sustainability. The quality of water is one of the first subjects that should be analyzed before the installation of an aquaculture project, and the students that've taken part in this study, were able to convert words used in graduation to make it possible to teach the importance of periodical evaluations to activity enthusiasts.

Keywords: environment, pisciculture, knowledge transfer.

\section{INTRODUÇÃO}

A aquicultura brasileira vem acompanhando o crescimento da aquicultura mundial, e de acordo com os dados estatísticos da Associação Brasileira de Piscicultura (PeixeBR, 2020), o Brasil produziu cerca de 758.006 toneladas de pescado no ano de 2019, atingindo um crescimento de 4,9\% em relação ao ano anterior. E dentre as diversas espécies cultivadas no Brasil, destaca-se a tilápia do Nilo, que ultrapassou a marca de 430.000 toneladas produzidas, se mantendo no topo entre as espécies de criação (PEIXE BR, 2020).

O estado do Mato Grosso do Sul vem apresentando números em constante crescimento, segundo a PeixeBR (2019) a produção do estado atingiu 25.850 toneladas, o equivalente a 3,58\% da produção nacional, impulsionada pela criação de pacu, patinga, pintado e, não fugindo do contexto nacional, da tilápia, e, de acordo com o levantamento realizado em 2020, já é o oitavo maior produtor de peixes do Brasil, com 29.800 toneladas (PeixeBR, 2020). A perspectiva é positiva para a produção da cadeia de pescado nos próximos anos, pois além de possuir uma abundância hídrica e temperaturas elevadas que é propícia para a produção de diversas espécies, há também insumos para produção de 
rações, bem como o estabelecimento de empresas que estão investindo no setor, o que contribui para alavancar ainda mais a produção da região.

Apesar da produção de peixe estar em plena expansão e ser uma alta fonte biológica fornecedora de proteínas, cuidados devem ser tomados quanto a sua criação para que a atividade não se torne uma fonte de poluição ambiental, muito impulsionada pela alta densidade de estocagem, excesso de oferta de rações para os animais ou até mesmo alimentação com dietas e frequências irregulares proporcionando um desbalanço de nutrientes, ocasionando menor aproveitamento da ração pela espécie cultivada (Silva et al., 2018).

Ainda em relação às questões ambientais, o conhecimento das condições da água e dos diversos fatores que atuam no metabolismo desses sistemas pode fornecer subsídios para minimizar os impactos gerados pelo lançamento de efluentes (Mercante et al., 2007). Assim, os parâmetros abióticos como temperatura, transparência, oxigênio dissolvido, $\mathrm{pH}$ e amônia, fornecem uma série de informações de extrema importância aos sistemas de criação, desde como o ambiente está se comportando até como as consequências que ocorrerão em função dessa água, para a produtividade do sistema.

Para o desenvolvimento da aquicultura sustentável e ecologicamente correta é importante ressaltar a necessidade da prática de um manejo específico das áreas aquícolas (Bueno et al., 2008). O efetivo monitoramento e acompanhamento das condições do ambiente aquático e suas características e respostas em relação às funções naturais e influências antrópicas no sistema auxiliarão a validação para a regulamentação de empreendimentos aquícolas, de acordo com as leis em vigor (Ayrosa et al., 2006). E nesse sentido, a falta de capacitação ou de assistência técnica ao produtor é um ponto crucial no sucesso da atividade.

O objetivo desse projeto foi propiciar aos alunos do curso de Engenharia de Aquicultura, uma rápida vivência técnica a campo, no sentido de serem propagadores de conhecimento, repassando aos pequenos produtores rurais do assentamento Itamarati, Ponta Porã - MS a importância da qualidade de água para a piscicultura em um contexto econômico, garantindo a produção sustentável.

\section{METODOLOGIA}


O início do projeto consistiu no aprendizado e condicionamento de 20 alunos do curso de Engenharia de Aquicultura da Universidade Federal da Grande Dourados (UFGD), os quais estavam matriculados na disciplina de Qualidade de água. Anteriormente ao início das aulas foi submetido um projeto à Pró-Reitoria de Extensão e Cultura, intitulado "Qualidade de água como alicerce para a produção sustentável de pequenos produtores de peixes" que se enquadra nos Objetivos de Desenvolvimento Sustentável (ODS) número 6 estabelecido pela Organização das Nações Unidas (ONU) para assegurar a disponibilidade e gestão sustentável da água e saneamento para todas as pessoas.

Os vinte alunos matriculados na disciplina fizeram parte da primeira etapa do projeto que consistiu na capacitação dos mesmos a respeito dos parâmetros de qualidade de água, sua importância e seus desafios frente à produção sustentável de peixes, bem como foi discutido com os acadêmicos a importância de uma transferência correta de informação técnica.

Neste sentido, os parâmetros de qualidade de água repassado em sala de aula foram apresentados aos participantes do projeto, bem como a importância de mantê-los dentro de faixas adequadas a atividade aquícola, assim como as alternativas de manejo. Dentre essas variáveis estão o oxigênio dissolvido $\left(\mathrm{mg} \mathrm{L}^{-1}\right), \mathrm{pH}$, transparência $(\mathrm{cm})$, temperatura $\left({ }^{\circ} \mathrm{C}\right)$, alcalinidade $\left(\mathrm{mg} \mathrm{L}^{-1}\right)$, amônia total $\left(\mathrm{mg} \mathrm{L}^{-1}\right)$, amônia tóxica $\left(\mathrm{mg} \mathrm{L}^{-1}\right) \mathrm{e}$ nitrito $\left(\mathrm{mg} \mathrm{L}^{-1}\right)$, que são os principais fatores para se obter uma boa qualidade de água para a produção da maioria das espécies de peixes cultivadas na região.

A segunda etapa do projeto ocorreu ao longo do segundo semestre do ano de 2019, com alguns alunos que continuaram no projeto. Essa etapa foi realizada no Assentamento Itamarati, município de Ponta Porã - MS (Figura 1), e consistia na apresentação do projeto para os pequenos produtores rurais. As propriedades foram selecionadas de acordo com um levantamento de ações extensionistas da UFGD, em que houve reuniões prévias realizadas com todos os assentados interessados e posteriormente, numa segunda reunião para triagem e avaliação dos seguintes aspectos: a) disponibilidade de iniciar o empreendimento; b) possibilidade de expansão da unidade de cultivo existente; c) ser produtor rural do Assentamento Itamarati e d) quantidade e qualidade da água disponível. Neste ínterim, nas propriedades visitadas existiam a instalação de viveiros escavados para criação de peixes ou ao menos uma fonte de abastecimento de água, no caso de 
propriedade de futuros produtores de peixes. Foram realizadas nove visitas in loco, semanalmente, e nessas visitas foram realizadas coletas de água, que por vezes eram nos viveiros já existentes ou, no caso dos produtores rurais que não possuíam ainda esses sistemas, os locais que iriam servir como fonte de abastecimento de água para o sistema produtivo, podendo ser a água da cachoeira, córrego, nascente ou poço.

Antes das visitas às propriedades foi elaborado uma ficha (Anexo 1) contendo as informações referentes à bibliografia especializada e disponibilizada em um quadro com os valores recomendados de cada variável analisada, a faixa de tolerância pelas espécies de regiões tropicais, e uma coluna para ser preenchida de acordo com os dados observados na propriedade. Conforme o produtor ou os alunos participantes preenchiam as informações, já havia a recomendação abaixo, informando se aquele valor observado estava dentro ou fora da normalidade. Esta mesma ficha informava aos produtores o que deveria ser feito em caso de valores fora do recomendado ou da faixa de tolerância pelas espécies.

Foram visitados seis pequenos produtores, que possuíam viveiros escavados e três fontes de abastecimento de água, totalizando nove locais de amostragem, e foram assim descritos: produtor A: longitude, 55.659690 e latitude: 22.210750; fonte de abastecimento de água B, longitude: 55.650423 e latitude: 22.190188; produtor C, longitude: 55.692639 e latitude: 22.237460; fonte de abastecimento de água $\mathrm{D}$, longitude: 55.710821 e latitude: 22.225256; produtor E, longitude: 55.464777 e latitude: 22.135070; produtor F, longitude: 55.652754 e latitude: 22.201624; produtor G, longitude: 55.654821 e latitude: 22.204604; produtor H, longitude: 55.662297 e latitude: 22.211549; e fonte de abastecimento de água I, longitude: 55.467019 e latitude: 22.137174 . 


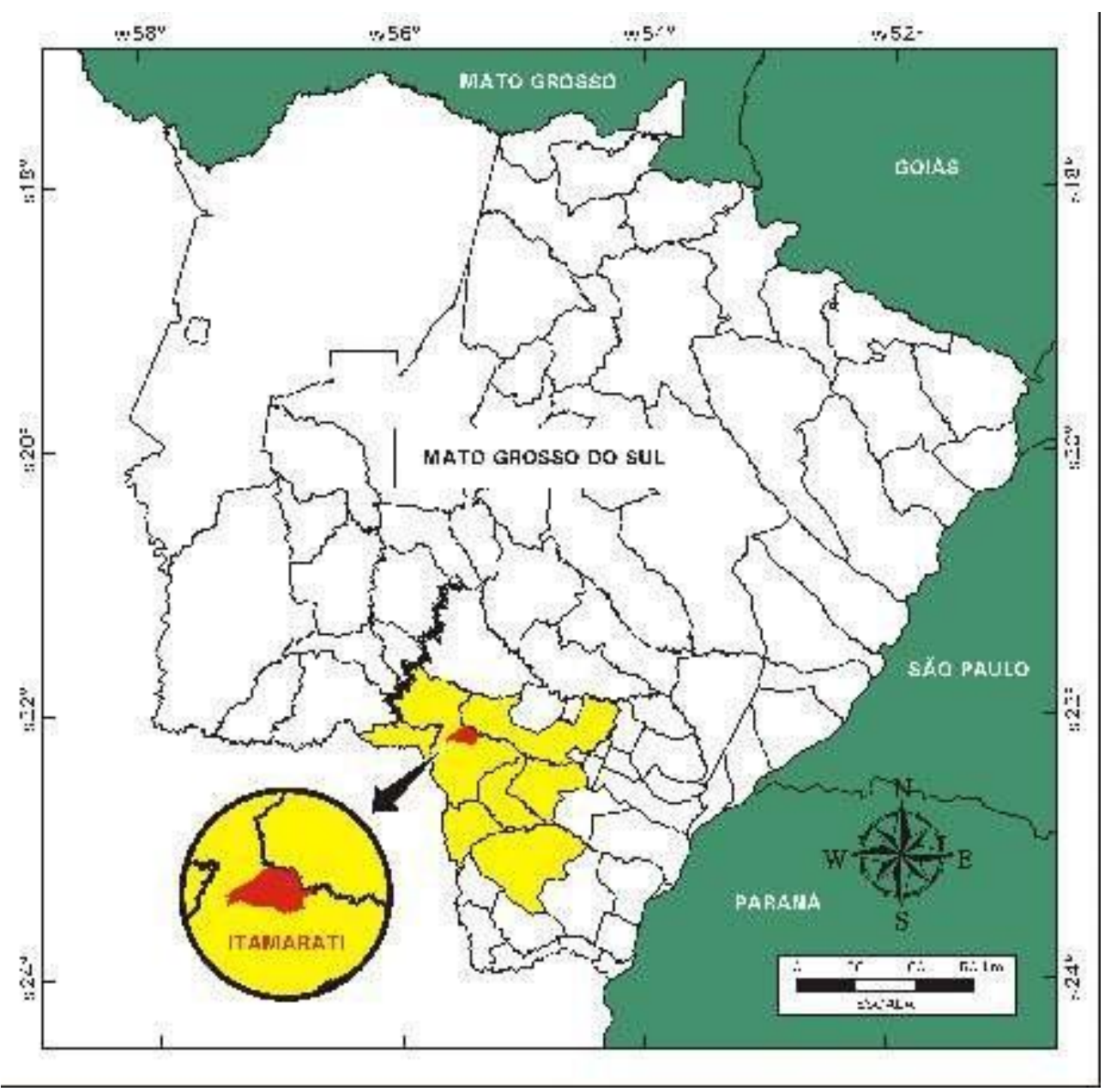

Figura 1. Localização do Assentamento Itamarati no município de Ponta Porã-MS.

Fonte: Disponível em: 〈https://www.researchgate.net/figure/Localizacao-da-regiao-doentorno-do-Assentamento-Itamarati-em-Ponta-Pora-MS_fig1_280732717>. Acessado em: 23 mar. 2020.

Todas as análises de água foram realizadas com auxílio de kit’s colorimétricos portáteis, com exceção do oxigênio foi obtido por meio de um oxímetro portátil, onde os alunos faziam e ensinavam os pequenos produtores demostrando para os mesmos, como é simples, rápido e prático fazer essas aferições, transferindo o que aprenderam na primeira etapa do projeto. Logo após as análises, os alunos anotavam os resultados da coleta da água daquele local para a ficha disponibilizada aos produtores e explicavam quais as alternativas de manejo que deveriam ser adotadas em função da resposta obtida nas análises. 
Assim sendo, foi discutido com os produtores as práticas e manejos necessários para correção, quando algum dos parâmetros estivesse fora da faixa ou mesmo como realizar a manutenção da água, tendo assim, uma boa qualidade para a prática da aquicultura. Sempre demonstrando com a maior clareza e de forma sucinta como manusear os equipamentos, como realizar a leitura dos resultados e como interpretá-los de uma maneira prática e rápida.

\section{RESULTADOS E DISCUSSÃO}

Embora seja dito que a qualidade de água deve ser vista como o primeiro aspecto fundamentador da atividade, ou seja, deve possuir condições mínimas para o sucesso de alguma criação; é importante que se tenha um acompanhamento dos parâmetros químicos e físicos da água, bem como ela esteja em abundância e disponível o ano todo, durante as visitas foi possível perceber que os pequenos produtores rurais não têm conhecimento sobre a qualidade de água e o impacto que ela pode proporcionar à produção.

Após a obtenção dos dados coletados, os mesmos foram anotados em uma ficha e comparados aos valores de referência que já existem e que estavam disponíveis. O intuito era que esses produtores conseguissem verificar rápido como deveriam agir de acordo com as análises realizadas.

As variáveis analisadas nas propriedades em geral encontram-se em boas condições para criação da maioria dos organismos aquáticos e seguem o estabelecido na Resolução CONAMA 357 de 2005. Entretanto, alguns locais apresentaram variações que estão melhor descritas abaixo.

O oxigênio dissolvido, principal variável para manter os organismos vivos, esteve em condições para o cultivo em cinco localidades amostradas, acima de $5 \mathrm{mg} \mathrm{L}^{-1}$ (Silva et al., 2016), que é a situação favorável para a criação de organismos aquáticos. Para esses produtores foi explicado que deveriam tentar permanecer com a água nessas condições.

Para os produtores que não estavam dentro desses valores, totalizando quatro propriedades, foi sugerido que vissem o contexto como um todo, já que o oxigênio é incluído por meio do fitoplâncton, possivelmente essas águas eram muito transparentes e o manejo deveria incluir a adubação da água, como descrito na ficha de visita (Anexo 1). No caso dos níveis de oxigênio baixo nas fontes de captação, foi instruído que o produtor 
que captasse de poço, deixasse essa água descansando em local aberto antes do mesmo ser incluído nos viveiros, devido à alta concentração de $\mathrm{CO}_{2}$.

Os valores obtidos do $\mathrm{pH}$ se encontravam dentro do recomendado pela Resolução CONAMA no 357/2005 (CONAMA, 2005). E, desse modo, foram ressaltados para os produtores que se o pH estiver abaixo da concentração tolerada para a produção de organismos aquáticos deve-se fazer o manejo de correção do solo, aplicando calcário agrícola na dose de duas toneladas por hectare, e, se no caso o $\mathrm{pH}$ for acima do recomendado deve-se fazer a renovação total da água, além de diminuir a densidade estocada (Silva et al., 2016). Aqui um cuidado maior deve ser verificado em função da densidade de animais estocados nos viveiros, fato que também foi conversado com os produtores.

A transparência da água nada mais é que a indicação do quanto aquela água possui de produtividade primária, sendo recomendada que a transparência seja de 30 a $40 \mathrm{~cm}$ (Silva et al., 2016). De um modo geral, nas propriedades, a transparência da água estava nos padrões estabelecidos pela Resolução CONAMA n 357/2005 (CONAMA, 2005). Para os piscicultores que possuíam água com altos valores de transparência, o recomendado foi se atentar com crescimento de plantas aquáticas indesejadas, além de secar o viveiro e adubá-lo para que assim possa haver no local uma produção primária que suprisse a necessidade do próprio ambiente.

Já para aqueles que possuíam águas com baixos valores de transparência, ou seja, uma água muito turva ou esverdeada em excesso, foi dito para observarem alguns sinais que podem ajudar a detectar problemas consequentes à esta alta produtividade primária existente, além da água muito verde, peixes boquejando na superfície no início da manhã é um sinal da falta de oxigênio disponível devido ao consumo deste gás no período noturno. E, caso isso ocorrer ou continuar ocorrendo, deve-se suspender ou diminuir a alimentação até que o ambiente retorne ao normal. E em casos extremos, deve-se fazer a renovação da água do local, pois a falta de oxigênio á noite pode levar os animais à morte. Nos casos das águas de abastecimento, esta variável não foi obtida, justamente por ser um parâmetro de referência à viveiros em criação.

Os peixes são animais que regulam a temperatura do corpo em função da temperatura da água (Silva et al., 2016). Por isso, a importância de sempre manterem os 
animais nas faixas recomendadas, entre 26 a $32^{\circ} \mathrm{C}$ para que não afete o crescimento e engorda da maioria das espécies de peixes tropicais (Lima et al., 2013).

No presente estudo, os dados coletados foram em um período chuvoso o que culminou em baixas temperaturas, com limites entre $18-32{ }^{\circ} \mathrm{C}$. Para os piscicultores que não estavam dentro da faixa ideal, aconselhou-se reduzir o fornecimento da ração ou até mesmo a suspensão dos alimentos aos animais, respeitando a tabela de alimentação que eles seguem, para evitar desperdícios de recursos e piora na qualidade de água.

A alcalinidade, importante variável para manutenção e estabilidade do pH durante o dia, esteve abaixo do recomendado na maioria das propriedades amostradas, oito no total, estando em concentrações menores que $20 \mathrm{mg} \mathrm{L}^{-1}$ (Lima et al., 2013).

Silva et al. (2016) descreveram alguns sinais práticos dentro da piscicultura que apontam a baixa alcalinidade, ou seja, quando a transparência da água estiver alta ou quando houver variações brutas dos parâmetros da qualidade da água durante o dia. Caso isso ocorrer, o manejo correto é realizar a calagem, para que assim a adubação do viveiro seja trocada com o ambiente, e assim sendo reestabelecida uma alta produção do fitoplâncton. Todos os valores obtidos da amônia total e amônia tóxica estavam dentro do recomendado para a produção aquícola estabelecido pela Resolução CONAMA 357 de 2005. O que se torna compreensível, pois no diálogo com os piscicultores, nenhum relatou perda de apetite ou até mesmo alterações comportamentais dos animais, que são sinais comuns caso essas variáveis estejam fora dos padrões estabelecidos pela legislação.

Por fim, os valores obtidos do nitrito se encontraram estáveis, com valores inferiores a $0,03 \mathrm{mg} \mathrm{L}^{-1}$, considerado então, um valor adequado para a criação de peixes (Lima et al., 2013).

Perda de apetite e peixes boquejando na superfície no final da tarde (Silva et al., 2016) são sinais que o nitrito está a cima do valor recomendado na água de cultivo. Para isso, o manejo correto a se fazer visando se adequar ao parâmetro ótimo é alimentar os animais de forma moderada, utilizando rações de alta digestibilidade, além de evitar a fertilização excessiva, principalmente quando se utiliza adubo orgânico, e manter níveis ideais de oxigênio dissolvido no viveiro (Corrêa, 2018). Vale ressaltar, que valores elevados de nitrito podem resultar na redução de crescimento dos peixes até mesmo a mortalidade de todo o plantel dos animais, caso esse valor fique elevado por um período extenso. 


\section{CONSIDERAÇÕES FINAIS}

A comunidade que foi assistida pôde manusear os equipamentos, coletar a água e fazer as análises com os kits colorimétricos. Aprenderam quais os valores recomendados para os parâmetros aferidos e de como atingir e manter esses valores durante todo o período de criação, sempre enfatizando uma produção sustentável da piscicultura e dessa maneira, visando conseguir um maior lucro, pois, na verdade, se cultiva primeiramente a água e a produção do peixe é somente uma consequência disso. Puderam também, observar se em sua propriedade é possível produzir organismos aquáticos, e sendo positivo, quais eram as espécies mais recomendados baseados na qualidade de água verificada.

Os acadêmicos que participaram do projeto fizeram a "ponte" entre a academia e o setor produtivo, sendo que a tarefa mais intensa foi a transferência de informações que aqui chamamos de difusão de conhecimentos. Sendo a assistência técnica a parte mais carente de uma produção, é extremamente relevante colocar esses futuros profissionais em contato real com produtores, até mesmo aprender a conversar e trocar vivências.

Seria interessante que o projeto continuasse para verificar se houve um ganho por parte dos produtores e futuros produtores de peixes desse Assentamento assistido pelo projeto, bem como verificar se as instruções continuarão sendo utilizadas e se efetivamente serão postas em prática.

\section{REFERÊNCIAS}

AYROSA, D.M.M.R.; FURLANETO, F.P.B.; AYROSA, L.M.S. Regularização dos projetos de tanques-rede em águas públicas continentais de domínio da união no Estado de São Paulo. São Paulo: Instituto de Pesca, 2006. (Boletim técnico, n. 36).

BUENO, G.W.; MARENGONI, N.G.; GONÇALVES JÚNIOR, A.C.; BOSCOLO, W.R.; TEIXEIRA, R.A. Estado trófico e bioacumulação do fósforo total no cultivo de peixes em tanques-rede na área aquícola do reservatório de Itaipu. Acta Scientiarum Biological Sciences, v. 30, n. 3, p. 237-243, 2008. 
CONAMA. Conselho Nacional do Meio Ambiente. Resolução no 357, de 17 de março de 2005. Dispõe sobre a classificação dos corpos de água e diretrizes ambientais para o seu enquadramento, bem como estabelece as condições e padrões de lançamento de efluentes, e dá outras providências. Brasília: Diário Oficial da União. 2005. Disponível em: http://www.mma.gov.br/port/conama/legiabre.cfm?codlegi=459.

CORRÊA, R. O. Qualidade da água na piscicultura continental. - Cartilha. EMBRAPA, PDF (32p.), 2018, Brasília, DF. Disponível em: https://ainfo.cnptia.embrapa.br/digital/bitstream/item/187706/1/TC-32-17-CARTILHAQualidade-Agua-V05.pdf.

LIMA, A. F.; SILVA, A. P. da; RODRIGUES, A. P. O.; BERGAMIN, G. T.; TORATI, L. S.; PEDROZA FILHO, M. X.; MACIEL, P. O. Qualidade da água: piscicultura familiar. - Cartilha. EMBRAPA, 2013, Divinópolis, TO.

MERCANTE, C. T. J.; MARTINS, Y. K.; CARMO, C. F.; OSTI, J. S; PINTO, C. S. R. M.; TUCCI, A. Qualidade da água em viveiro de Tilápia do Nilo (Oreochromis niloticus): caracterização diurna de variáveis físicas, químicas e biológicas, São Paulo, Brasil. Revista Bioikos, p.79-88, Campinas, jul./dez., 2007.

PeixeBR. Anuário da Piscicultura 2019. Peixe BR - Associação Brasileira da Piscicultura, São Paulo, 2019.

PeixeBR. Anuário da Piscicultura 2020. Peixe BR - Associação Brasileira da Piscicultura, São Paulo, 2020.

SILVA, W.L.M.; FROZZI, J.C.; FONSECA, J.C.; SALVADOR，J.S.P.; RIBEIRO, P.N.T.; COSTA CAMPOS, M.C. Sustentabilidade na aquicultura: dimensões social, econômica e ambiental - uma revisão de literatura. Revista EDUCAmazônia, v. 20, n. 1, p. 87-108, 2018. 
SILVA, T. S. C., BORGHESI, R., INOUE, L. A. K. A., GUIMARÃES, M., Noções para aquicultura familiar: qualidade de água - cartilha. EMBRAPA, 2016, Dourados, MS. 
Anexo 1.

Monitoramento da qualidade de água de pequenos produtores rurais no distrito de Itamarati, Ponta Porã, MS.

Projeto: Qualidade de água como Alicerce para a produção sustentável de pequenos produtores de peixes (ODS 6)

Localização das análises:

Nome do Produtor:

Data de coleta:

\section{O que você deve saber?}

Nós criamos água! Se os peixes comem, nadam ou permanecem vivos nos tanques ou viveiros, é porque a água está boa.

Então, antes de sabermos criar os peixes, devemos cuidar da água para que ela sempre esteja com "qualidade".

Abaixo há uma tabela indicando como os parâmetros de água devem se comportar, compare com os seus resultados e verifique se os mesmos estão dentro da faixa indicada.

Tabela 1. Faixa adequada dos parâmetros de água com o objetivo de criação de peixes.

Valor recomendado, valores observados na sua propriedade e faixa tolerada pela maioria das espécies.

\begin{tabular}{|l|l|l|l|}
\hline Parâmetros & Valor recomendado & $\begin{array}{l}\text { Valores observados na } \\
\text { propriedade }\end{array}$ & $\begin{array}{l}\text { Faixa tolerada pela } \\
\text { maioria das espécies }\end{array}$ \\
\hline $\begin{array}{l}\text { Oxigênio dissolvido } \\
(\mathrm{mg} / \mathrm{L})\end{array}$ & $>5,0$ & & $3,0-10,0$ \\
\hline $\mathrm{pH}$ & $6,5-8,0$ & & $6,0-9,0$ \\
\hline Transparência $(\mathrm{cm})$ & $30-50 \mathrm{~cm}$ & & - \\
\hline Temperatura $\left({ }^{\circ} \mathrm{C}\right)$ & $24-29$ & & $18-32$ \\
\hline Alcalinidade $(\mathrm{mg} / \mathrm{L})$ & $>40$ & & - \\
\hline Amônia total $(\mathrm{mg} / \mathrm{L})$ & $<0,50$ & & 2,0 a 3,0 \\
\hline Amônia tóxica $(\mathrm{mg} / \mathrm{L})$ & $<0,20$ & & 0,20 \\
\hline Nitrito $(\mathrm{mg} / \mathrm{L})$ & $<0,50$ & & 0,50 \\
\hline
\end{tabular}




\section{O que fazer quando algum dos parâmetros estiver fora da faixa?}

Geralmente a troca de água ajuda quando alguns parâmetros estiverem fora da margem tolerável.

Oxigênio baixo - Procure fazer trocas de água. Se for possível promova a aeração/oxigenação da água dos viveiros, pois rapidamente os níveis de oxigênio se elevam.

pH - Se o pH estiver alto ou baixo, procure fazer a troca de água. Outras medidas que podem ser tomadas: com o $\mathrm{pH}$ alto (na faixa de 8,5 a 9,0), pare de alimentar os peixes, pois a água está muito alcalina. Possivelmente sua alcalinidade está baixa, havendo grandes variações de $\mathrm{pH}$ durante o dia e a noite. Quando o $\mathrm{pH}$ estiver baixo (menor que 6,0 ), tente fazer manejos de correção de solo (seria interessante realizar esse manejo antes de colocar os peixes). A aplicação de calcário na dose de 2 toneladas/hectare, ajuda a elevar para níveis acima de 6,0 (cuidado, pois se o $\mathrm{pH}$ estiver acima de 6,0, você pode elevar demais o valor e ser prejudicial).

Transparência - Águas muito claras não apresentam produtividade primária suficiente para os peixes se alimentarem nem para produzir oxigênio na água. Se você estiver fazendo essa análise e o disco de Secchi desaparecer apenas quando já estiver com mais de $60 \mathrm{~cm}$ de profundidade, sua água não está bem adubada. Para melhorar você deve adubar o viveiro para que ele fique com água em coloração esverdeada, assim, não haverá falta de oxigênio. Se a transparência estiver abaixo de $30 \mathrm{~cm}$, pode haver o risco de faltar oxigênio em alguns horários (madrugada e amanhecer), pois há um excesso de fitoplâncton (água verde). Para resolver isso a melhor forma é fazer a troca de água.

Amônia - A amônia é o produto de excreção dos peixes, portanto sempre vai estar presente na água. Você deve tomar cuidado para que não tenha demais, pois isso se torna prejudicial aos animais, ao ponto de todos morrerem.

O que pode levar a água a ficar com níveis altos de amônia? A primeira coisa é o excesso de ração! Como a ração de peixes apresenta muita proteína, esse composto é liberado via brânquias rapidamente durante o metabolismo das proteínas.

O que fazer para que a amônia não aumente? Trate seus peixes regularmente, mas não em excesso (utilize as tabelas alimentares para lhe ajudar se for necessário). Verifique a concentração de oxigênio dissolvido na água! Ambientes com baixo oxigênio têm maior 
capacidade de transformar a amônia em um composto tóxico. Águas com pH e temperaturas mais elevadas também apresentam maior toxidez da amônia.

Em casos onde a amônia aumentar, o que deve ser feito? Se você verificar altos teores de amônia, a primeira coisa a ser feita é suspender a ração, e em seguida iniciar o processo de troca de água, se for possível, coloque algum equipamento de aeração/oxigenação para ajudar nesse período.

Nitrito - O nitrito é um composto secundário no processo de oxidação da amônia. Em ambientes confortáveis, a amônia é convertida em nitrito e posteriormente transformada em nitrato (um composto menos tóxico), aí é utilizada pelas plantas e organismos no próprio viveiro. Lembrando: essas transformações ocorrem em ambientes com temperatura, $\mathrm{pH}$ e oxigênio dissolvido em concentrações favoráveis.

Se o nitrito estiver alto o que acontece? Bom, o nitrito tem a capacidade de oxidar a molécula que transporta o sangue dos peixes, então se você verificar peixes com sangue marrom (metahemoglobina), quer dizer que os mesmos foram acometidos. Importante: Alta concentração de nitrito leva os peixes à morte por asfixia!

O que fazer caso verifique níveis altos de nitrito? A primeira coisa é suspender a alimentação. Inicie também a rápida troca de água do viveiro. Se possível aplique sal na água, pois o sal irá ajudar nas brânquias dos peixes, fazendo com que o nitrito não fique tão tóxico nesse momento.

Universidade Federal da Grande Dourados

Curso de Engenharia de Aquicultura

Projeto de Extensão: Qualidade de água como Alicerce para a produção sustentável de pequenos produtores de peixes 